\title{
Are Principals Prepared to Lead in Schools with Diverse Student
}

\section{Populations Using Invitational Leadership?}

\author{
Barbara N. Martin ${ }^{1 *} \&$ Catherine M. Miller ${ }^{2}$ \\ ${ }^{1}$ ELHD, University of Central Missouri, Warrensburg, Missouri, USA \\ ${ }^{2}$ Raytown Public Schools, Raytown, MO, USA \\ *Barbara N. Martin, E-mail: bmartin@ucmo.edu
}

Received: September 18, 2017 Accepted: September 28, 2017 Online Published: October 9, 2017

doi:10.22158/jecs.v1n2p198

URL: http://dx.doi.org/10.22158/jecs.v1n2p198

\begin{abstract}
This inquiry sought to create meaning via an invitational leadership lens about how principals are prepared to lead in schools with diverse student populations. Data revealed principals' perceptions about preparation related to invitational leadership emphasized contradictions between principals' inviting-oriented rhetoric and their underlying beliefs regarding diverse student populations. Implications include opportunities that principal preparation programs include invitational leadership at the forefront of social justice leadership, as they prepare leaders working with diverse student populations.
\end{abstract}

\section{Keywords}

invitational leadership, social justice leadership, principal, preparatory programs

\section{Introduction}

Twenty-first century Principals need to improve skills that are critical for providing an optimistic and inviting social justice-learning environment for a highly diverse student population. Despite the calls from Race to the Top and other federal reforms that emphasize all educators preparing students for college and careers, social injustice in the form of inadequate access to quality educational resources is a real barrier to meeting these goals. DeMatthews and Mawhinney (2014) noted, "persistent historical and structural marginalization not only exists but is pervasive in education [and] underscores the fact that eliminating inequities is an ongoing struggle rather than a singular battle fought and won over the course of a school year" (p. 875). In schools where embedded social justice is not in the culture, responding to injustice is piecemeal and reactive (Miller \& Martin, 2014). Furthermore, Furman (2012) argued for the need for new ways to enhance leadership preparatory programs when arguing, "These persistent inequalities demand new approaches to transformative action in schools and, thus, new approaches to educational leadership" (p. 212). While scholars have made progress in theorizing the 
themes undergirding leadership for social justice, these inquiries have presented limited data about what leadership preparation for social justice orientations in practice looks like and how the skill set for aspiring leaders needs developing (Furman, 2012; Marshall \& Oliva, 2010).

Brown (2006) asserted, "Leadership preparation programs must change in a way which provides increased knowledge to improve equity and equal opportunities for all racial and ethnic groups" (p. 588). Moreover, McKnight and Martin (2015) argued, "It is vital that higher education institutions incorporate invitational leadership characteristics when cultivating and developing aspiring leaders" (p. 63). Consequently, a need exists for a new model of leadership that provides a new equity direction and the invitational leadership model uniquely answers this appeal (Stillion \& Siegel, 2005). Since invitational leaders concentrate on the creation of organizations that are people-centered and success oriented while dealing with all aspects of the organization (Purkey \& Novak, 2016; Purkey \& Siegel, 2003), the coupling of the two lenses is important. As Egley (2003) contended, "The research on the effects of Invitational Education Theory in the educational administrative process is relatively new as compared to other theories about leadership" (p. 57). Consequently, Furman (2012) argued for "a unifying concept regarding leadership for social justice because it captures the dynamic interplay between the reflection and action needed for this work in schools" (p. 213). We contend that the use of aligning invitational leadership dimensions with this self-reflection and action of social justice leadership will allow for the enhancement of social justice leadership orientation within school settings, especially those with changing student demographics.

For this study, two research questions emerged, which guided this study:

a) What are the perceptions of Principals regarding the effectiveness of their preparation programs in preparing them to lead in demographically changing or urban settings about education equity, and inviting practices?

b) How do Principals create the conditions for the promotion of invitational learning in their demographically changing schools?

\subsection{Conceptual Framework}

Despite the significance placed on social justice leadership over the last few years in educational leadership literature, the explicit understanding of the leadership remains obscure. Actual practices of social justice leadership skills are just emerging. For example, Theoharis (2008) examined Principals who self-identified as social justice believers and discovered three shared leadership traits: a sense of "arrogant humility", passion about their work in schools, and a "tenacious" commitment to social justice. Even though these interrelated themes have emerged that have begun to inform practice, there is still much that educators do not know about social justice leadership orientation. Undeniably, an inquiry has only begun to identify some of the issues, and challenges Principals confront when they employ social justice leadership orientations in their school settings to create inviting environments (Theoharis, 2007).

Social justice has often identified as an absence of opportunities for children based on gender, 
economic status, ethnicity, and race, especially in a context of high-stakes testing (Alsbury \& Whitaker 2007). While Goldfarb and Grinberg (2002) viewed social justice as "the exercise of altering arrangements by actively engaging in reclaiming, appropriating, sustaining, and advancing inherent human rights of equity, equality, and fairness in social, economic, educational, and personal dimensions" (p. 162). Dantley and Tillman (2010) postulated a theoretical definition of social justice leadership that combined the ideas of transformative moral leadership and social justice.

Consequently, Theoharis (2007) focused on this myriad of definitions to guide his classification of social justice leadership. This definition noted social justice leadership exists when school leaders "make issues of race, class, gender, disability, sexual orientation, and other historically and currently marginalizing conditions in the United States central to their advocacy, leadership practice, and vision" (p. 223). Addressing specifically, changing demographics and race, Gooden and Dantley (2012) highlighted the significance of the impact of self-reflection and inspection when demonstrating a social justice orientation, which ultimately should raise leaders' awareness regarding racial oppression and discrimination. Conversely, DeMatthews (2016) and DeMatthews and Mawhinney (2014) emphasized while this self-awareness is essential in social justice leadership orientation, there are essential barriers, both technical and structural in schools that need to be addressed through the use of processes and policy if equity reform is going to be successful. DeMatthews, Edwards and Rincones (2016) further argued,

Leadership for social justice begins with addressing deficit thinking about and within marginalized communities, then facilitating a critical dialogue on the status quo within the school and community, and finally more fully developing and sustaining a school-community partnership capable of expressing a more preferred future and charting a new course (pp. 6-7).

DeMatthews (2016) additionally noted this social orientation process as principals' experiences, values, and principles, allowing the leader to create and modify their role in initiatives, goals, and visions of their schools ultimately guiding the social justice interactions of their school and community towards a more inviting community. To achieve social justice leadership through practice, policy, and total community involvement, we postulate the understanding and application of the dimensions of invitational leadership as the portal to achieve such social justice orientation, in not only leadership behaviors and practice, but also preparation for aspiring leaders.

As McKnight and Martin (2015) stressed, "If a leader seeks an inclusive learning environment, one that creates a climate of encouragement and belonging, then the theory and practice of invitational leadership is one to consider" (p. 64). Furthermore, the invitational leadership model seeks to invite all stakeholders to succeed (Stillion \& Siegel, 2005). As noted by Day, Harris and Hadfield (2001) invitations are "messages communicated to people which inform them that they are able, responsible and worthwhile" (p. 34). These messages are corresponded through "inter-personal action, but also through institutional policies, programmes [sic], practices, and physical environments" (Day et al., 2001, p. 34). Purkey and Novak (2016) highlighted a democratic ethos when arguing, "Invitation 
Education reflects this Democratic Ethos by emphasizing deliberative dialogue, mutual respect, and the importance of shared activities" (p. 7). Moreover, Purkey and Novak (2016) noted an inviting environment must entail the foundation of this democratic ethos, along with understanding one's perceptions, which at the core is self-concept or the constructing of ones' understanding of how we fit into the world.

To change a school environment, the leader must understand and apply the five basic elements of invitational education. To create this "inviting stance" (p. 14), by the educators within a school setting, must demonstrate these five based elements of intentionality, care, optimism, respect, and trust (Purkey \& Novak, 2016). Invitational leadership has been created based upon the basic assumptions that exemplify invitational leaders: intentionality, care, optimism, respect, and trust. These five principles serve as core values to invitational leadership (Day et al., 2001).

When the school leader incorporates intentionality on the inviting stance within a school, then they are creating "a sustained framework for creating and maintaining a dependably inviting environment" (Purkey \& Novak, 2016, p. 15). Additionally, the leader should identify all individuals within the school have an individual need for "joy and fulfillment in the production of something valuable" (Purkey \& Novak, 2016, p. 15). This component of intentionality is a vital and core part of the theory. As Stillion and Siegel (2005) concluded: "knowing what we intend to bring about as well as how we intend it to happen gives clarity and direction to our work" (p. 15).

Schmidt (2002) highlighted an intentional care for others as essential in understanding an inviting environment. For instance, Purkey and Novak (2016) postulated, "In Invitational Education, care is the ongoing desire to link significant personal means with worthwhile societal ends" (p. 15). Stillion and Siegel (2005) articulated that invitational leaders work to establish an optimal environment where educators can achieve their goals and potential while participating in the shared vision of the group. Stillion and Siegel (2005) promoted the optimism of a leader as one "who can reframe problem situations as opportunities and view the impossible as merely difficult" (p. 14). "Invitational leadership intentionally creates positive physical places to work and puts into place policies that reflect the optimism of the leader and lead to trust and respect among workers" (Stillion \& Siegel, p. 9).

The value of respect is one of the innate needs of all human nature (Purkey, 1992; Purkey \& Novak, 2016) and "lead to an inviting, inclusive workplace where diversity is the norm, and every individual can flourish" (Stillion \& Siegel, 2005, p. 12). Purkey and Novak (2016) noted, "Whether educators also exhibit personal and professional respect among their peers is largely determined by whether they accept the assumption that they are able, valuable, and responsible" (p. 17).

Likewise, related to respect is the value of the trust. Purkey and Siegel (2003) defined trust as "having confidence in the abilities, integrity, and responsibilities of ourselves and others" (p. 12). Moreover, Purkey and Novak (2016) postulated a specific framework by which schools can become "invitational" by concentrating on five areas contributing to success or failure: places, policies, programs, processes, and people. As the Purkey and Siegel (2003) concluded the, "five powerful factors-people, places, 
policies, programs, and processes (the five P's) - are highly significant for their separate and combined influence on invitational leadership" (p. 104). The inclusion of the five P's significantly assists in making invitational leadership a unique and holistic leadership model (Stillion \& Siegel, 2005; Purkey \& Novak, 2016), and one that can enhance a leader's social justice orientation.

The intent of this inquiry was not to prescribe action plans for impoverished settings but rather to illuminate the potential for a different reality; a reality where school leaders develop, and where change is possible. Also, the researchers wanted to emphasize the elements and principles designed for educational leaders that require developing the knowledge, skills, and dispositions necessary to understand invitational leadership and its implications for our schools. To this end, Marshall and Oliva (2010) positulated, “... Deconstructing those realities in order to disclose the multiple ways schools and their leadership reproduce marginalizing and inequitable treatment of individuals because their identities are outside the celebrated dominant culture" (p. 22).

\section{Method}

In the choice of inquiry approaches, decisions are made in the process of designing research. Creswell (2003) proposed the following questions: "What strategies of inquiry will inform the procedures?" "What methods of data collection and analysis will be used?" (p. 5). For the given study, education leaders at the principal level, were the primary focal point; seeking a clearer understanding of the nature of school leadership, and the preparation required to become an education leader who is culturally responsive, socially just, and inviting in their school settings. In this way, "Qualitative researchers are interested in understanding the meaning people have constructed, that is, how they make sense of their world and the experiences they have in the world" (Merriam, 1998, p. 6).

Thus, a multi-case study design was utilized to understand the implications of the data. Yin (2003) argued when the research "aims to produce a first-hand understanding of people and events" (p. 3) a case, or unit of analysis, is appropriate. A multi-case study may "strengthen the findings ... [through] deliberate and contrasting comparisons" (Yin, p. 6) of the data. The primary method of data collection was semi-structured interviews with the Principals participating in the study, along with observations, and document analysis.

\subsection{Participants}

This multiple case study was conducted in three purposefully selected (Crewell, 2003) districts, because of their metropolitan location and diverse student populations. Also, each principal was purposely selected to "facilitate the expansion of the developing theory" (Bogdan \& Biklen, 2007, p. 73). This selection was on his or her experience (five+ years), gender, race, and level (elementary, middle, high school), along with having received their leadership degrees from different Universities. The resultant participants, one Caucasian male high school principal, one African American female middle school principal, and one Caucasian female elementary school principal provided the researchers with multiple perspectives. 


\subsubsection{Instrumentation Protocol}

Each in-person interview consisted of fifteen questions and lasted approximately two hours. After the initial interview, follow-up telephone interviews were conducted to explore emerging themes further, lasting an hour. These semi-structured interviews were conducted consisting of open-ended questions (Fraenkel \& Wallen, 2003) relating to the effectiveness of the participant's preparation regarding invitational leadership and social justice orientation taught in their preparatory program. Additional questions were asked identifying practicing behaviors that demonstrated an inviting school climate with a social justice orientation.

Also reviewed were school documents provided by the principal. Examples of such documents analyzed were schedules, student and teacher handbooks, improvement plans, achievement data, and correspondence to parents. Before the interviews, gathered were the demographic data about the size of the school and district, socio-economic level of the school, the school district, and the school community. Analyzed through the lens of invitational and social justice leadership were all appropriate school documents.

Observations were the final data collection protocol used in this inquiry. The researchers spent a week in a complete observer role (Creswell, 2003), studying each subject in his/her natural professional setting(s). Observations give the researchers the ability to gain firsthand experience, record information as it occurs, and witness events that may not be covered or expressed in interviews and focus groups (Creswell, 2014).

\subsubsection{Data Analysis}

According to researchers (Creswell, 2014; Flick, Scott, \& Metzler, 2014), the grounded theory allows the researcher to purposefully select sites or individuals to gather and analyze data that best fit the research questions designed to obtain useful information. Data was gathered and analyzed using a grounded theory approach in a manner that information could be coded and triangulated to identify common themes. Seidman (2013) contended creating a systematic process for filing transcripts, tracking participants, and accurately labeling are necessary steps in managing information. The analysis via an iterative process identified common themes and triangulated multiple data sources (Huberman \& Miles, 2002). Specifically, using the following framework, the data were analyzed and the following emergent themes identified. The framework as MacDonnall (2014) identified,

Invitational Education also focuses on four elements of educational environments on a spectrum that includes: 1) Intentionally Disinviting (purposefully hostile); 2) Unintentionally Disinviting (the interaction is intended to be positive, but the impact is negative); 3) Unintentionally Inviting (the interaction is positive but inconsistent); and 4) Intentionally Inviting (interactions convey optimism, respect, and trust because they are reliable and consistent at both the individual and organizational level) (pp. 43-44). 


\section{Result}

The following themes emerged: 1) Addressing Social Justice Inequities through the Six P's and 2) Acknowledging the "Disparity Gap" but not the "Inviting Gap". In accordance, these two themes vividly depict how public school principals perceive the educational needs of a diverse population and how they respond to issues of equity. However, noted was a lack of understanding of how to practice invitational leadership to obtain a social justice orientation, due perhaps to the lack of said content within their preparatory programs (see Figure 1).

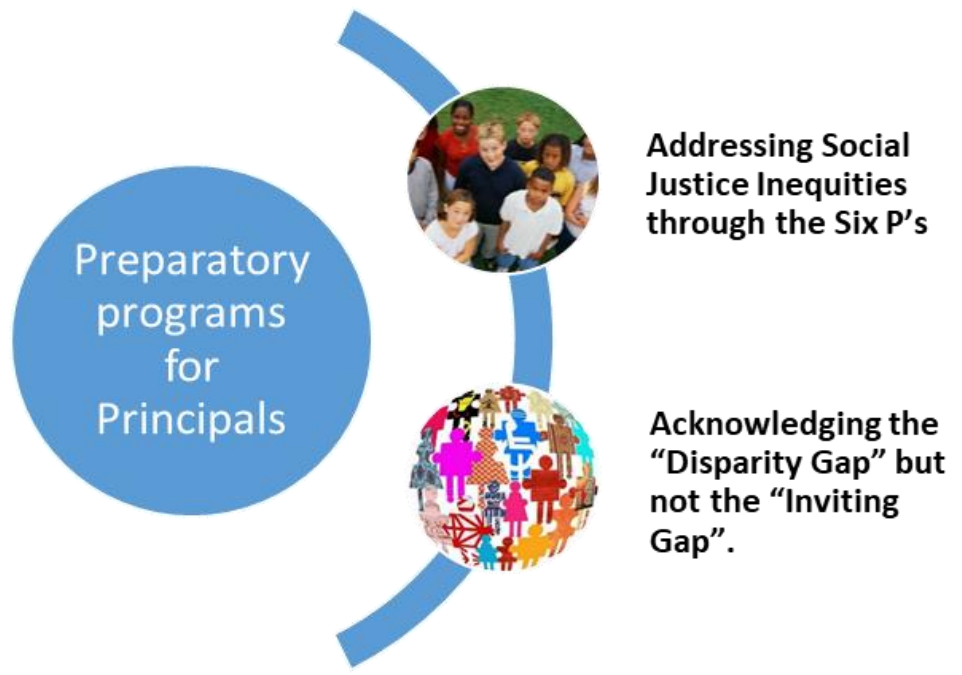

Figure 1. Emergent Themes from the Data

\subsection{Addressing Social Justice Inequities through Six P's}

\subsubsection{People}

The first P, People, focused on human interactions between students, teachers and the community in educational environments, and in this research specifically, on the social justice interactions that created an inviting learning environment for all. In light of the school's diversity, the elementary Principal said that her toughest challenges involved attempting to build positive relationships with African American and Hispanic parents. She emphasized an equity-oriented stance regarding the diversity of the student body at her school. However, she spent considerable time characterizing the Black population in a negative light. For example, her response to understanding the culture of her building was definitely from a white privilege point of view:

... listening to conversations ... the level of noise in my cafeteria is a perfect example because the Black culture is a louder culture for the most part. Women dominate it ... the women in that culture are large and in charge ... they really are ... so don't mess with their baby. So just looking at that culture...looking at how my PTA meetings have changed over time ... used to have a lot of support...not as much now from my Black or Hispanic families. 
She further expressed strong opinions that varied according to the families' cultural backgrounds. The Principal described African American parents as "hesitant to trust" and "not supportive". When probed on how this trust could be enhanced, the Principal could not give any specific strategies that she knew of or had received training on regarding social justice or intentional inviting behaviors. To the contrary, she noted that Hispanic families "for the most part are intact ... mom and dad ... and they are supportive of the school community. And they ask really good questions. I very rarely have issues with my Hispanic population". Again when probed regarding how this trust evolved, she reflected, "Nothing special occurred to build that trust it just happened". Therefore, while this Principal did not demonstrate hostile behaviors towards the community she served, her perceptions indicated there were no intentional inviting behaviors used to build care, trust, or even respect within the diverse population.

While the high school Principal conveyed some inviting equity-oriented intentions in discussing the demographic change, he did not discuss taking any proactive steps to address the negative attitudes expressed by students. He cited, “I don't see color ... I really don't ... when I make decisions, I don't think in color. I don't really think you should think in those terms. You should think of what is best for your kids". He spoke of color-blindness as an apparent badge of efficacy reflecting his neutrality, seemingly unaware of the cultural complexities and social tensions that could be affecting his school.

There used to be friction with outside Black kids and Black kids ... Kids come in and have difficulty becoming part of a school with our Black kids. That is probably our biggest problem ... Is Black kids accepting Black kids from the outside.

When probe further to give any specific examples of how you engage teachers in creating an environment, which would enhance the respect and trust of these students, the Principal was at a loss of words. He even indicated that such respect and trust should be expected. Again while not necessary uninviting, there were no indications of intentional inviting behaviors being used or even understood.

\subsubsection{Places}

The 2nd P, Places, focuses on surroundings and the intentional safe places created in school settings for discourse on social justice issues. The middle school Principal recognized cultural bias in some of her teachers, but was reluctant to pinpoint specific examples and instead focused her attention on holding teachers accountable and having difficult conversations. She was a self-described "reflective person" who believed in educating all children "in spite of all the things happening over here in their lives". "We can't change that [students' home lives] so what are we going to do about it?" In light of her conversation about demographic change and the cultural difference being enriching, she seemed reticent in her ability to lead a diverse educational community. For example, she may have unintentionally marginalized her Latino population when she explained:

My Hispanic kids, for example, are a very loyal group of children and families. So loyal in fact that they won't snitch on each other. If there is an issue and I am trying to get information ... They won't tell. So, being sensitive to that ... have to understand how to talk to those kids.

When asked about critical discourse being addressed by the teachers, the middle school Principal noted 
that time is provided during each faculty meeting to discuss how to approach these conversations regarding race or ethnicity. She noted, "At each faculty gathering we begin the meeting with discussing ways in which teachers can create time for students to discuss any issues facing them regarding equity issues". She also noted that they have advisory meetings once a week, to discuss these topics. When probed as to how these conversations were having an impact on creating an inviting environment, she said she had no answer.

\subsubsection{Programs}

The 3rd P, Programs, addresses curriculum within school settings and also within the school leaders' preparatory programs that address invitational leadership with a social justice orientation. A consensus emerged among the participants that minimal emphasis was placed on their preparation coursework to prepare for leading in diverse schools with an invitational leadership focus. None of the Principals espoused their preparation experiences as particularly conducive to leading diverse schools. Although two Principals remembered coursework that provided discussion along these lines, overall not provided within their preparation programs was the opportunity to gain a contextual or experiential understanding of equity or of creating inviting environments. The middle school Principal explained that she had taken time to consider the question before the interview yet was not able to draw upon any discussion of invitational leadership theory in her preparatory program, nor in team meetings regarding curriculum development within her school setting. She did add the notion, "Overall I have witnessed few teachers wanting or willing to engage in discussion of equity for students. I guess the assumption is that our classrooms and school are equitable".

\subsubsection{Processes}

The fourth P, Processes, focuses on ways that inviting interactions to involve all stakeholders and includes their voices when developing instructional programs and finding instructional resources. The school leaders in this study unequivocally demonstrated persistence working toward the goal of high achievement for every child. Consequently, during the interviews, a great deal of time was spent discussing strategies, plans, and resources Principals used to address increasing achievement scores and closing the achievement gap. On the one hand, Principals' spoke of the strategies used to raise achievement. On the other hand, not discussed was the concern of why it might be important to have students who can use their academic skills to be critical citizens and challenge injustices in society. It seemed ample for these school leaders to focus on student achievement perhaps at the expense of preparing students to live in a diverse community. The high school Principal discussed the district directives and his school's focus only on standardization of the curriculum:

We're narrowing that down to common assessments, student work review ... This year we are doing an early release, and our building is working with RPDC (Regional Professional Development Center) developing PLC's (professional learning communities).

When asked how teachers, parents, or students were involved in this professional community process, he replied that most of the work was coming from the district office. So even while noting that teachers 
were involved in discussing issues within the school setting, how various stakeholders were involved in the processes was not.

The principals in each of the schools perceived their situation as "high pressure" to meet the requirements of the state testing standards. The elementary school Principal focused most of her attention on data despite the lackluster results from the prior school year. She shared, "last year we were the highest in reading scores but didn't meet AYP" and "... in communication arts our Black population didn't meet, and in math, our Hispanic and School as-a-Whole didn't meet". Therefore, while she discusses the lack of progress of some students within her school, she did not address how any self-reflection by the staff, or perhaps the lack of an inviting learning environment might be the source of the lack of empowerment or optimism by all of the students.

When confronted, principals in this study identified good teaching and meeting the needs of every child every day. However, their responses seemed ambiguous. To this end, after a detailed explanation of how his building was using data to analyze the strengths and weaknesses of individual students and groups of students, the high school Principal was terse and vague in his response. Furthermore, when asked if the work he and his teachers were doing to increase achievement and address the gap between majority students and English language learners, special education students, and other minority populations was working:

Probably sped, yes, more so ... we don't have a lot of ESL kids, got a few ... got one teacher a couple of hours ... our Hispanic population does pretty well ... more of a female population. We do have more kids from different countries than we did. We had kids from two to three Middle Eastern countries ... Iran kids ... Iraq kids ... kids from about four different Central American countries ... pretty good on English.

When pressed about identifying good instructional behavior to meet the needs of all students, the high school Principal scarcely discussed the idea:

I have changed my focus the last couple of years and focused more on instructional leader rather than management. I have changed my walkthrough format ... last year to going in and leaving a note with a smiley face, great job, to these (provided the researcher a copy of the current form). It has two things on it-Marzano and district ... then tear off ... give to the teacher ... that way they get feedback.

Again, no discussion or insights on the various learning needs of different populations of students, nor any recognition that an inviting learning environment would empower student learning.

\subsubsection{Policies}

The fifth P, Policies, includes organizational policies that reflect inclusion and democratic principles. The principals focused on the policies that they had implemented to help students but seemed to lack skills in understanding the needs of students of poverty [people] or the "processes" needed to enhance the skills of the teachers in meeting those needs. Understanding how to develop the people in their organizations for a social justice orientation, from teachers to students, was lacking in their discourse. Furthermore, the principals perceived their situation as "high pressure" to meet the requirements of the 
state testing standards. After a detailed explanation of how her building was using data to analyze the strengths and weaknesses of individual students and groups of students, the elementary school Principal was vague in her response when asked if the work her teachers were doing addressing the gap between majority students and other minority populations was working. The researchers further confirmed from each of the Principals that they considered their schools to be "inclusive" despite their use of resource rooms, pullout programs, and lower-track courses that were not as inviting. Thus, according to Marshall and Oliva (2010), in so doing, "educators are ironically segregating students in the name of inclusion" (p. 179), and thus not creating inviting environments for all students.

\subsubsection{Politics}

The sixth P, Politics, addresses the subtleties of power and privilege across a spectrum from individual to community levels; and action for social change through political and professional leadership and advocacy. Not all three principals had a concise, nor transparent awareness of the degree of inequity present in their schools. When asked if equities existed, all three of the principals were emphatic in their response of "NO" to the inquiry. While the middle school Principal acknowledged the need to engage in these conversations, she did not indicate if any of her teachers engaged in difficult dialogue about race or ethnicity, or other inequality their students or the community might identify. Thus, not discussed was the impact these conversations might or might not have had on decisions regarding responsiveness to equity. When asked how they would define white privilege, the high school and elementary Principals' did not know how to respond or appeared not to want to respond. The middle school Principal did acknowledge an understanding of the existence of white privilege, but noted, "As an African American, who is supervising a majority of white teachers, I am hesitant to discuss white privilege, unless privately ...". When then asked how many teachers had she privately discussed the concept with, her response was, "One".

Consequently, the principals were well-versed in analyzing disaggregated testing data and comfortably knowledgeable in addressing the achievement gap using the data to guide their action plans, but when asked how they identified inequities within their building or supported the development of socially just practices or inviting behaviors, the responses were austere. Moreover, while their behaviors were not hostile, there was little evidence of intentional inviting behaviors towards a social justice orientation. For example, the high school Principal initially rebuked the question by declaring, "that makes no sense at all" but after clarification by the researchers, he responded:

We address inequities through policies, but I don't know if it is because it is a black issue or white issue or race. Attendance and poverty ... well there's white schools with attendance and poverty that they address with different policies ... So don't know that the policies are based on inequities but more on need.

The middle school Principal responded with equal ambiguity:

First and foremost when I have a parent that wants to come in that I have an inkling they may want to play the race card, immediately I say ... you are probably thinking that I can't be fair because your 
child is ... whatever [race].

However, later in the interview, she drew the researchers' attention to a disparate number of Black males sent to the recovery room (behavior intervention strategy):

It worries me that when I look at the statistics in the recovery room ... It is Black males. So how are we missing that population or why are they still not coming around in our school? Am I doing something not to meet their needs?

When asked if she ever advocated for teachers to examine their behavior intervention strategies based on inequities, she responded she had not, but perhaps she would in the future. Thus, perhaps the principals acknowledged the disparity gap, but not the inviting gap. See the visualization of the use of the Six P's towards a social justice orientation in Figure 2.

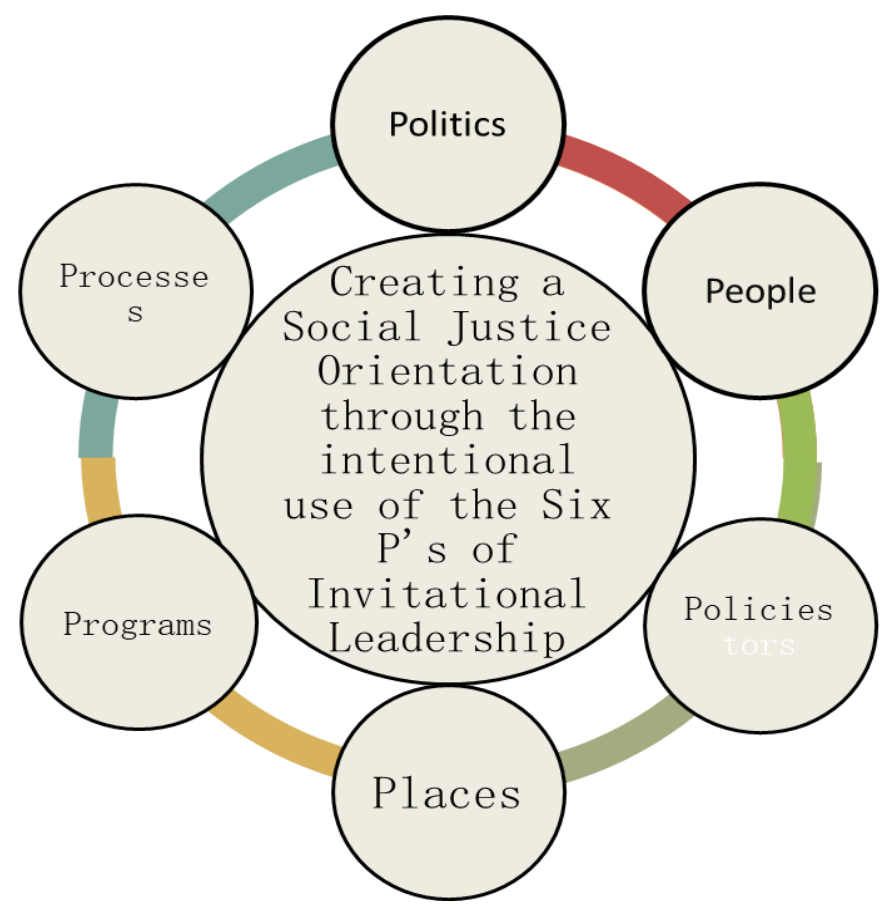

Figure 2. Six P's within Social Justice

\subsection{Acknowledging the "Disparity Gap" but not the "Inviting Gap"}

Because of demographic change and the growing presence of people of color in historically White neighborhoods, many school leaders faced with their own biases often founded on ignorance and fear (Cooper, 2009). The elementary Principal recounted the days when the school was "swarming" with PTA moms and the hub of the upper-middle-class community. Then, over time in addition to a poor economy and more working parents, a new 900-unit apartment complex was built. "It is a HUD housing. They need every service in the book because they're for the most part poor parents and so they come up here and immediately want to bring all their baggage with us". Such examples of the deficit and uninviting thinking can perpetuate inequities (McKenzie, Skrla, \& Scheurich, 2006) and 
shed light on underlying assumptions, values, and attitudes that embedded in the school culture. The high school Principal also conveyed equity-oriented intentions in discussing the demographic change, but he did not discuss taking any proactive steps to address the negative attitudes expressed by students or teacher. As he noted, “I don't see color ... I don't think you should think in those terms. You should think of what is best for your kids". This badge of efficacy as viewed by this principal through his "color-blindness" indicated his lack of preparedness in the cultural complexities of his school. The middle school Principal had strong convictions about serving all children equally well. "I just believe in equity ... equal for all kids. I want everything fair for kids ...”. As an African American administrator, she recognized cultural bias in some of her teachers but was reluctant to confront them on the issues, thus avoiding the opportunity to create an inviting environment for all (see Figure 3).

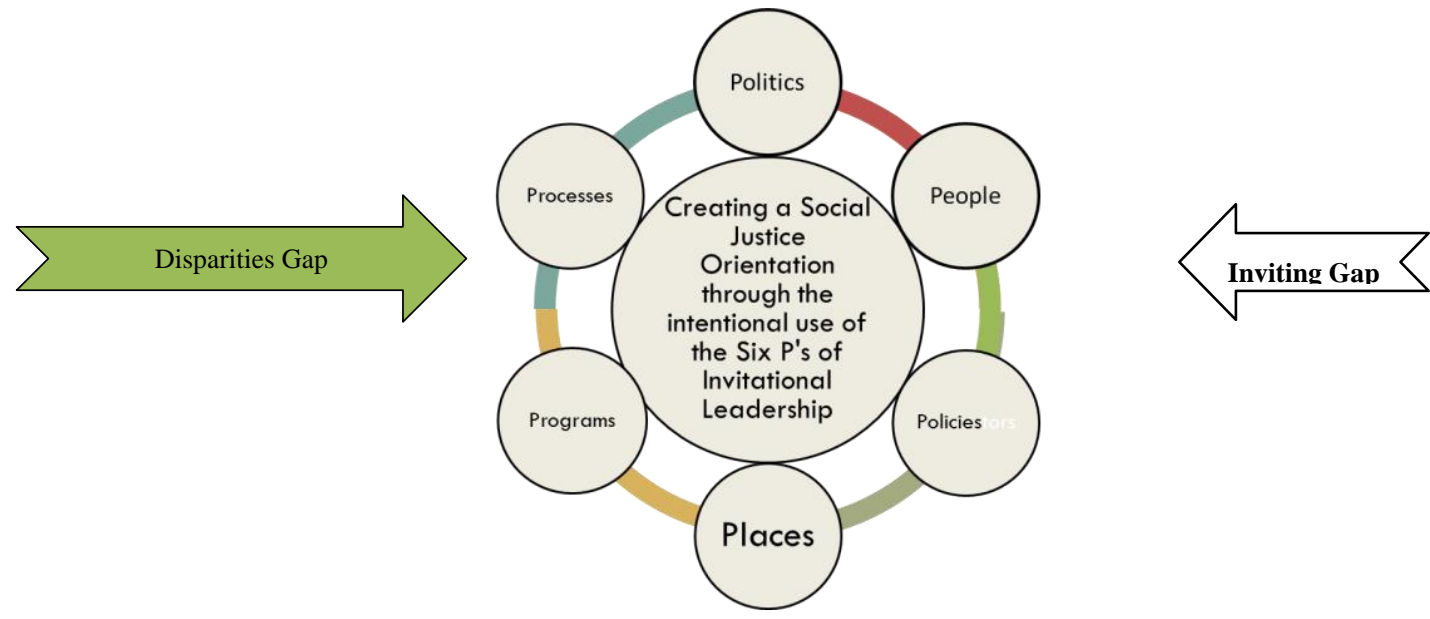

Figure 3. Acknowledging the "Disparity Gap" but not the "Inviting Gap"

\section{Conclusions and Implications}

These datasets were analyzed through the six P's of invitational leadership. Also, the continuum of the four elements of educational environments (intentionally disinviting, unintentionally disinviting, unintentionally inviting, and intentionally inviting (MacDonnall, 2014) were used, concluding the behaviors, and the self-reflection of these principals fell primarily within two of the four elements. Not observed, nor supported by the data, were two of the elements: intentionally disinviting and consistent use of intentionally inviting behaviors. From this narrative, it appears that these principals are unintentionally disinviting some of their school's population or are not consistent in conveying optimism, respect, and trust to their entire student population.

When further analyzed the data revealed, the majority use of unintentionally disinviting behaviors might be due to the lack of preparation through their leadership preparatory programs. Moreover, since these principals attended three different Universities, suggested is a lack of training principals are 
receiving on the constructs of Invitational and Social Justice Leadership within preparatory programs. Not only are there inconsistencies in awareness, but the practice of inviting behavior were not frequently observed.

Since the theoretic underpinning of invitational leadership encompasses principles focuses on self-perception and concept, caring, and democratic processes (MacDonnall, 2014), it can provide opportunities to address the inequities that exist in these schools by constantly examining the interactions of people, places, processes, programs, policies, and politics. Consistent with an invitational approach, the findings of this case study help to identify potential avenues for improving relationships between individuals and communities, and relationships between individuals and institutions. Educational programming and policy development are key to making principals aware that services need to be made responsive and relevant to all users, particularly those marginalized.

These researchers concluded the goal of achieving academic success with students from demographically changing schools populations dominates the discourse of leaders in the field regardless of level. However, to effectively achieve this goal requires educational leaders to restructure what expectations they hold for all students and faculty focused on equity. Furthermore, principals need to lead in reorganizing how their schools support equity in teaching and to learn to enhance and create an inviting environment for all students through intentional inviting actions.

Unfortunately, in the case of these three principals, there is a significant disconnect between a leader's perceived accountability to close the achievement gap and their lack of responsiveness and inability to identify the biases, assumptions, and inequities that may be perpetuating the very gap they are attempting to close by not using inviting behaviors. These leaders are addressing the achievement gap through substantive programs and policies, but are failing to acknowledge the disparity gap through these policies and programs that hinder their ability to move toward equity in schooling and creating an inviting environment for all.

Regarding principal preparedness in creating inviting learning environments in demographically changing schools, preparation programs are inadequate. Principals lacked opportunities within their programs to examine their own personal and professional beliefs, to develop skills to identify inequitable policies and practices, and employ inviting behavior, to name a few. Invitational leadership theory, coupled with a social justice orientation should be at the forefront of all preparatory leadership programs.

The implications for this inquiry have an impact on higher education preparatory programs and pre K-12 school districts. The findings supported the need for principal candidates to participate in preparation programs designed to build the capacities of invitational leaders with a social justice orientation. Moreover, a substantive, coherent preparation program focused on opportunities for candidates to reflect on how their values and experiences are essential for leaders, and could easily result in candidates better prepared to address diversity issues related to culture, equity, and social justice in urban school settings. By applying the tenets of invitational leadership and social justice 
leadership, these candidates can effectively address achievement and disparities between majority and minority populations.

Once a candidate has achieved a principal position, it is the responsibility of the school district to train and retrain them to create and sustain an inviting school environment. The study findings also suggested a need for principals in the field to have the strategies and tools necessary to identify, challenge, and counteract discrimination and prejudice, while creating an inviting culture. In the review of the literature, the researchers identified two reasonable strategies, namely culture audits and equity audits. The use of culture audits to recognize fundamental organizational values and beliefs, and equity audits to identify racial inequalities within programs and practices will build the capacity of school leaders. Their vision should be to develop a more comprehensive, insightful understanding of equity and inequity relationships in their current systems, and the need to create an inviting school environment for all.

Through this inquiry, the researchers uncovered a constant theme: the desire to be an equity-oriented leader overshadowed by the lack of understanding of personal biases and complex contradictions evidenced when attempting to address inequities. Therefore, if graduates of educational administration programs are expected to take on new and necessary roles as defined by inclusiveness and activism, then leadership programs must prepare new leaders to implement the inviting structures and norms that result in inequitable schooling for all students.

\section{References}

Alsbury, T. L., \& Whitaker, K. S. (2007). Superintendent perspectives and practice of accountability, democratic voice and social justice. Journal of Educational Administration, 45(2), 154-174. https://doi.org/10.1108/09578230710732943

Berkovich, I. (2014). A socio-ecological framework of social justice leadership in education of Educational Administration, 52(3), 282-309.

Bogdan, R. C., \& Biklen, S. K. (2007). Qualitative research for education: An introduction to theory and methods (5th ed.). Boston, MA: Pearson/Allyn and Bacon.

Brown, K. M. (2006). Leadership for social justice and equity: Evaluating a transformative framework and andragogy. Educational Administration Quarterly, 42(5), 700-745. https://doi.org/10.1177/0013161X06290650

Cooper, C. M. (2009). Performing cultural work in demographically changing schools: Implications for expanding transformative leadership frameworks. Educational Administration Quarterly, 45(5), 694-724. https://doi.org/10.1177/0013161X09341639

Creswell, J. (2003). Research design: Qualitative, quantitative, and mixed methods approaches (2nd ed.). Thousand Oaks, CA: SAGE Publications.

Creswell, J. W. (2014). Research design: Qualitative, quantitative, and mixed methods approaches (4th ed.). Thousand Oaks, CA: SAGE. 
Dantley, M., \& Tillman, L. (2010). Social justice and moral transformative leadership. In C. Marshall \& M. Oliva (Eds.), Leadership for social justice: Making revolutions in education (2nd ed., pp. 16-29). Boston, MA: Allyn \& Bacon.

Day, C., Harris, A., \& Hadfield, M. (2001). Grounding knowledge of schools in stakeholder realities: A Multi-perspective study of effective school leaders. School Leadership \& Management, 21(1), 19-42. https://doi.org/10.1080/13632430120033027

DeMatthews, D. (2016). Social justice dilemmas: Evidence on the successes and shortcomings of three Principals trying to make a difference. International Journal of Leadership in Education, 1-15. https://doi.org/10.1080/13603124.2016.1206972

DeMatthews, D. E., Edwards, Jr., E., \& Rincones, R. (2016). Social justice leadership and family engagement: A successful case from Ciudad Juárez, Mexico. Educational Administration Quarterly, 1-39. https://doi.org/10.1177/0013161X16664006

DeMatthews, D., \& Mawhinney, H. (2014). Social justice leadership and inclusion: Exploring challenges in an urban district struggling to address inequities. Educational Administration Quarterly, 50(5), 844-881. https://doi.org/10.1177/0013161X13514440

DuFour, R., DuFour, R., \& Eaker, R. (Eds.). (2005). On common ground. Bloomington, IN: National Press.

Egley, R. (2003). Invitational leadership: Does it make a difference? Journal of Invitational Theory and Practice, 9, 57-70.

Emerson, R. M., Fretz, R. I., \& Shaw, L. L. (1995). Writing ethnographic field notes. Chicago, IL: University of Chicago Press.

Flick, U., Scott, W., \& Metzler, K. (2014). The SAGE Handbook of Qualitative Data Analysis. London, [England]: SAGE Publications Ltd.

Fraenkel, J. R., \& Wallen, N. E. (2003). How to design and evaluate research in education (5th ed.). New York: McGraw-Hill.

Furman, G. (2012). Social justice leadership as praxis: Developing capacities through preparation $\begin{array}{llll}\text { programs. Educational Administration } & \text { Quarterly, }\end{array}$ https://doi.org/10.1177/0013161X11427394

Gardiner, M. E., \& Enomoto, E. K. (2006). Urban school Principals and their role as multicultural leaders. Urban Education, 41(6), 560-584. https://doi.org/10.1177/0042085906294504

Goldfarb, K. P., \& Grinberg, J. (2002). Leadership for social justice: Authentic participation in the case of a community center in Caracas, Venezuela. Journal of School Leadership, 12, 157-173.

Gooden, M., \& Dantley, M. (2012). Centering race in a framework for leadership preparation. Journal of Research on Leadership Education, 7, 237-253. https://doi.org/10.1177/1942775112455266

Huberman, A. M., \& Miles, M. B. (2002). The qualitative researcher's companion. Thousand Oaks, CA: Sage Publications, Inc. 
MacDonnall, J. (2014). LGBT Health Care Access. Journal of Invitational Theory and Practice, 20, $38-60$.

Marshall, C., \& Oliva, M. (2010). Leadership for social justice: Making revolutions in education (2nd ed.). Pearson Education Inc.

McFalls, E. L., \& Cobb-Roberts, D. (2001). Reducing resistance to diversity through cognitive dissonance instruction: Implications for teacher education. Journal of Teacher Education, 52, 164-172. https://doi.org/10.1177/0022487101052002007

McKenzie, K., Skrla, L., \& Scheurich, J. (2006). Preparing instructional leaders for social justice. Journal of School Leadership, 16(2), 158-170.

McKnight C., \& Martin, B. (2015). Creating an effective educational environment for adult learners: A qualitative, multi-case study of off-campus center administrator's use of invitational leadership. Journal of Invitational Theory and Practice, 21(2), 49-67.

Miller, C. M., \& Martin, B. N. (2014). Principal preparedness for leading in demographically changing schools: Where is the social justice training? Educational Management Administration and Leadership.

Purkey, W. (1992). An introduction to invitational theory. Journal of Invitational Theory and Practice, l(1), 5-14.

Purkey, W., \& Novak, J. (2016). Fundamentals of invitational education (2nd ed.). IAIE.

Purkey, W., \& Siegel, B. (2003). Becoming an invitational leader: A new approach to professional and personal success. Atlanta, GA: Humantics.

Schmidt, J. J. (2002). Intentional helping: A philosophy for proficient caring relations. Upper Saddle River, NJ: Prentice Hall.

Seidman, I. (2013). Interviewing as qualitative research: A guide for researchers in education and the social sciences (4th ed.). New York, NY. Teachers college press.

Stillion, J., \& Siegel, B. (2005, November). Expanding Invitational Leadership: Roles for the Decathlon Leader. Retrieved from http://www.kennesaw.edu/ilec/Journal/articles/2005/siegel_stillion/expand_leadership/ex

Theoharis, G. (2007). Social justice educational leaders and resistance: Toward a theory of social justice leadership. Educational Administration Quarterly, 43, 221-258. https://doi.org/10.1177/0013161X06293717

Theoharis, G. (2008). Woven in deeply: Identity and leadership of urban social justice Principals. Education and Urban Society, 41, 3-25. https://doi.org/10.1177/0013124508321372 